\begin{tabular}{|c|l|}
\hline Title & $\begin{array}{l}\text { Constitutive Model for the Subsequent Time Dependent Deformations of Type 304 Stainless Steel at Room } \\
\text { Temperature }\end{array}$ \\
\hline Author(s) & Mayama, Tsuyoshi; Sasaki, Katsuhiko; Ishikawa, Hiromasa \\
\hline Citation & Advances in Engineering Plasticity and Its A pplications Pts 1-2, 229-234 \\
\hline Issue Date & 2004 \\
\hline Doc URL & http://hdl.handle.net/2115/15884 \\
\hline Rights & the original is available online at www.scientific.net \\
\hline Type & article (author version) \\
\hline Note & Key Engineering Materials, Volume 274-276 \\
\hline Information & A EPA 2004.pdf \\
\hline
\end{tabular}

Instructions for use 


\title{
Constitutive Model for the Subsequent Time-Dependent Deformations of Type 304 Stainless Steel at Room Temperature
}

\author{
Tsuyoshi Mayama ${ }^{1, a}$, Katsuhiko Sasaki ${ }^{2, b}$, and Hiromasa Ishikawa ${ }^{3, ~ c ~}$ \\ ${ }^{1}$ Division of Mechanical Science, Hokkaido University, N13W8, Kita-ku, Sapporo, Japan, \\ ${ }^{2}$ Division of Mechanical Science, Hokkaido University, N13W8, Kita-ku, Sapporo, Japan, \\ ${ }^{3}$ Department of Mechanical Engineering, Kyushu Sangyo University, Matsukadai 2-3-1, Higashi-ku, \\ Fukuoka, Japan \\ amayama-t@eng.hokudai.ac.jp, ${ }^{\text {b } k a t s u @ e n g . h o k u d a i . a c . j p, ~}{ }^{c}$ hiroishi@ip.kyusan-u.ac.jp
}

Keywords: Constitutive Model, Creep, Plasticity, Cyclic loading, Dislocation structure, TEM

\begin{abstract}
In this study, subsequent time-dependent deformation after cyclic preloading and a constitutive model is discussed. Stress-strain curves of $10^{\text {th }}$ and $30^{\text {th }}$ cycle of cyclic loading under the strain rate of $0.01 \% / \mathrm{sec}$ with the strain amplitude of $0.5 \%$ using Type 304 stainless steel at room temperature are almost same. However, creep and stress relaxation after the two cyclic loading are different due to the number of cycle of the cyclic preloading. The experimental results are simulated by a unified constitutive model. The model is constructed referring to dislocation observations after $10^{\text {th }}$ and $30^{\text {th }}$ cycles of cyclic loading by using TEM (Transmission Electron Microscope). The constitutive model shows good agreements with the experimental results of the subsequent creep and the subsequent stress relaxation.
\end{abstract}

\section{Introduction}

General purpose FEM codes are used for the structural analysis in many industrial areas. Most of the constitutive models incorporated into FEM codes are too simple to describe the complex deformations. Therefore, many constitutive models have been proposed [1-10]. To construct more accurate constitutive model, it is important to know the deformation mechanisms of polycrystalline metallic materials.

In this study, to clarify the relation between deformation and microscopic phenomena, material testing, microscopic observation, and constitutive modeling are conducted. First, using Type 304 stainless steel at room temperature, the subsequent creep and the subsequent stress relaxation after tension-compression cyclic loading are conducted. Then, the microscopic observation of specimens after cyclic loading are carried out by using TEM. Finally, a unified constitutive model is proposed to simulate the cyclic preloading and the subsequent time-dependent deformation. The constitutive model employs a viscoplastic potential, Prager-Ziegler type of the evolution equation of back stress, the stress-strain relation expressed by the power law, and the internal variable related to dislocation structural changes.

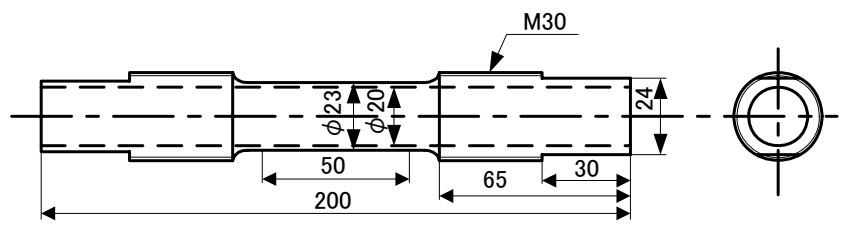

Fig.1 Geometry of specimen

\section{Experimental Procedures}

The specimen used in this study is a drawing tube of Type 304 stainless steel subjected to a solution heat treatment. The drawing tube has a $32 \mathrm{~mm}$ outer diameter and $6 \mathrm{~mm}$ wall thickness and is annealed by the manufacturer at $1070^{\circ} \mathrm{C}$ followed by water quenching for half an hour. Its chemical compositions are 
0.02C, $0.45 \mathrm{Si}, 1.09 \mathrm{Mn}, 0.030 \mathrm{P}, 0.005 \mathrm{~S}, 8.30 \mathrm{Ni}, 18.54 \mathrm{Cr}$, and Fe balanced in weight percent. The tubular specimens are machined from this tube as shown in Fig.1. The specimens are fabricated by metal cutting and then annealed to get an initial isotropic stress state. In this annealing process, the specimens are heated and maintained at $380^{\circ} \mathrm{C}$ for $120 \mathrm{~min}$ followed by air cooling. Young's modulus of the specimen at room temperature is $\mathrm{E}=200 \mathrm{GPa}$.

A servo-controlled axial-torsional testing machine is used for computerized testing data and data acquisition. Strain is measured using two strain gauges applied on diametrically opposite side of the specimen. The axial force is measured using the load cell incorporated in the machine.

There are two types of test in this work: (i) tensile creep tests after cyclic tension-compression loading with the constant strain amplitude $0.5 \%$ and the constant strain rate $0.01 \% / \mathrm{sec}$; (ii) stress relaxation tests after cyclic tension-compression loading with the constant strain amplitude $0.5 \%$ and a constant strain rate $0.01 \% / \mathrm{sec}$.

\section{Formulation of Unified Constitutive Model}

A unified constitutive model used in this study was proposed by authors previously [11]. Summary of the constitutive model is as follows. The viscoplastic potential is defined as in chaboche [12].

$$
\mathrm{F}=\frac{\mathrm{H}}{\mathrm{n}+1}\left\langle\frac{\bar{\sigma}-\mathrm{R}}{\mathrm{H}}\right\rangle^{\mathrm{n}+1}
$$

where \langle\rangle is MacAuley bracket and defined as $\langle x\rangle=\frac{1}{2}(x+|x|)$. H is the drug stress, $\mathrm{n}$ is the material constant and $\mathrm{R}$ is the flow stress. $\mathrm{R}$ is assumed as

$$
\mathrm{R}=\mathrm{R}_{\text {sat }}\left\{1-\lambda \exp \left(-\int\left|\dot{\bar{\varepsilon}}^{v}\right| d t / c\right)\right\}
$$

In Eq.(2) $\mathrm{R}_{\text {sat }}, \lambda$ and $c$ are material parameters.

The equivalent stress $\bar{\sigma}$ in Eq.(1) is represented as

$$
\bar{\sigma}=\sqrt{\frac{3}{2}\left(s_{i j}-\alpha_{i j}^{\prime}\right)\left(s_{i j}-\alpha_{i j}^{\prime}\right)}
$$

where $s_{i j}$ and $\alpha_{i j}^{\prime}$ are the deviatoric components of the stress tensor $\sigma_{i j}$ and the kinamatic back stress tensor $\alpha_{i j}$, respectively.

The normality hypothesis now becomes

$$
\dot{\varepsilon}_{i j}^{v}=\frac{\partial \mathrm{F}}{\partial \sigma_{i j}}=\left\langle\frac{\bar{\sigma}-\mathrm{R}}{\mathrm{H}}\right\rangle^{n} \frac{\sigma_{i j}-\alpha_{i j}}{\bar{\sigma}}
$$

The modified viscoplastic work rate is defined as the following equation.

$$
\dot{W}^{v}=\bar{\sigma} \dot{\bar{\varepsilon}}^{v}=\left(\sigma_{i j}-\alpha_{i j}\right) \dot{\varepsilon}_{i j}^{v}
$$

Then, from Eqs.(4) and (5), the following equation is given.

$$
\dot{\bar{\varepsilon}}^{v}=\left\langle\frac{\bar{\sigma}-\mathrm{R}}{\mathrm{H}}\right\rangle^{\mathrm{n}}
$$

From Eqs.(4) and (6), the flow rule can be explained by 


$$
\dot{\varepsilon}_{i j}^{v}=\frac{\dot{\bar{\varepsilon}}^{v}}{\bar{\sigma}}\left(\sigma_{i j}-\alpha_{i j}\right)
$$

From Eq.(7) the equivalent strain rate can be described as the follow;

$$
\dot{\bar{\varepsilon}}^{v}=\sqrt{\dot{\varepsilon}_{i j}^{v} \dot{\varepsilon}_{i j}^{v}}
$$

The following Ziegler's type of assumption for the evolution equation of the kinematic back stress is used here.

$$
\dot{\alpha}_{i j}=\left(\sigma_{i j}-\alpha_{i j}\right) \dot{\mu}
$$

where $\dot{\mu}$ is the scalar multiplying factor which is determined from Eqs.(3),(6) and (9). Eventually, the kinematic back stress rate is represented by

$$
\dot{\alpha}_{i j}=\left[\frac{\left(\sigma_{k l}-\alpha_{k l}\right) \dot{\sigma}_{k l}}{\bar{\sigma}^{2}}-\frac{\mathrm{H} \ddot{\bar{\varepsilon}}^{v}}{\mathrm{n} \overline{\bar{\sigma}}}\left(\dot{\bar{\varepsilon}}^{v}\right)^{\frac{1-\mathrm{n}}{\mathrm{n}}}-\frac{\dot{\mathrm{R}}}{\bar{\sigma}}\right]\left(\sigma_{i j}-\alpha_{i j}\right)
$$

In this paper, the following power law is used to represent the nonlinear viscoplastic modulus,

$$
\hat{\varepsilon}^{v}=\frac{\mathrm{K}}{\mathrm{E}}\left(\frac{\hat{\sigma}}{\mathrm{D}}\right)^{m} \hat{\sigma}
$$

where $\mathrm{E}$ is Young's modulus and $\mathrm{K}$ is a material constant. $\hat{\varepsilon}^{v}$ is the equivalent viscoplastic strain measured from $\varepsilon_{i j}^{R}$, which is the viscoplastic strain just before the loading direction changes. And $\hat{\sigma}$ is in general represented as,

$$
\hat{\sigma}=\left[\frac{3}{2}\left(s_{i j}-\hat{\alpha}_{i j}^{\prime}\right)\left(s_{i j}-\hat{\alpha}_{i j}^{\prime}\right)\right]^{1 / 2}
$$

where $\hat{\alpha}_{i j}^{\prime}$ is the deviatoric components of the center of the current yield surface $\hat{\alpha}_{i j}$ before the loading direction change. The back stress $\alpha_{i j}$ is memorized as $\hat{\alpha}_{i j}$ when the loading direction changes.

Because the residual viscoplastic strain $\varepsilon_{i j}^{R}$ is constant during the current loading, $\dot{\varepsilon}_{i j}^{v}$ is equals to $\dot{\hat{\varepsilon}}_{i j}^{v}$ and $\dot{\bar{\varepsilon}}^{v}=\dot{\hat{\varepsilon}}^{v}$ from $\varepsilon_{i j}^{v}=\hat{\varepsilon}_{i j}^{v}+\varepsilon_{i j}^{R}$. Then Eqs.(11) and (12) give

$$
\dot{\bar{\varepsilon}}^{v}=\dot{\hat{\varepsilon}}^{v}=\frac{\mathrm{K}}{\mathrm{E}}(\mathrm{m}+1)\left(\frac{\hat{\sigma}}{\mathrm{D}}\right)^{\mathrm{m}} \frac{1}{\hat{\sigma}}\left[\frac{3}{2}\left(\sigma_{i j}^{\prime}-\alpha_{i j}^{\prime}\right) \dot{\sigma}_{i j}^{\prime}\right]=\left\langle\frac{\bar{\sigma}-\mathrm{R}}{\mathrm{H}}\right\rangle^{n}
$$

In Eqs.(11) and (13), D and $\mathrm{m}$ are the functions depending on the accumulated inelastic strain at the memorized point. They can be assumed to be expressed by Eqs.(14) and (15), respectively.

$$
\begin{aligned}
& \mathrm{D}=\mathrm{D}_{(i)}\left\{1-\alpha \exp \left(-\int_{i-1}\left|\dot{\bar{\varepsilon}}^{v}\right| d t / a\right)\right\} \\
& \mathrm{m}=\mathrm{m}_{(i)}\left\{1-\beta \exp \left(-\int_{i-1}\left|\dot{\bar{\varepsilon}}^{v}\right| d t / b\right)\right\}
\end{aligned}
$$

where $\mathrm{D}_{(i)}$ and $\mathrm{m}_{(i)}$ become $\mathrm{D}_{0}$ and $\mathrm{m}_{0}$ during the initial loading before the loading direction changes, while $\mathrm{D}_{1}$ and $\mathrm{m}_{1}$ after the first loading direction change, $\mathrm{D}_{2}$ and $\mathrm{m}_{2}$ after the second loading direction change. In Eqs.(14) and (15) $\alpha, \beta, a$, and $b$ are material parameters. 


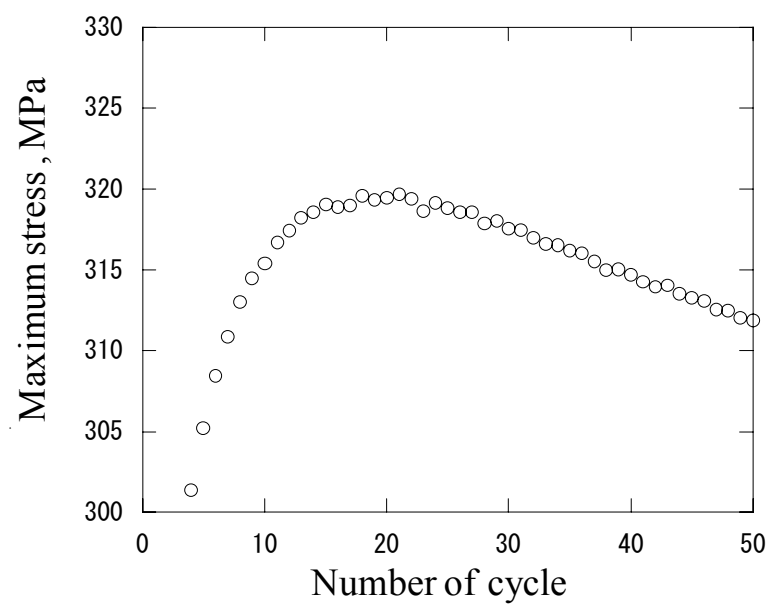

Fig.2 Maximum stress versus number of cycle during tension-compression cyclic loading

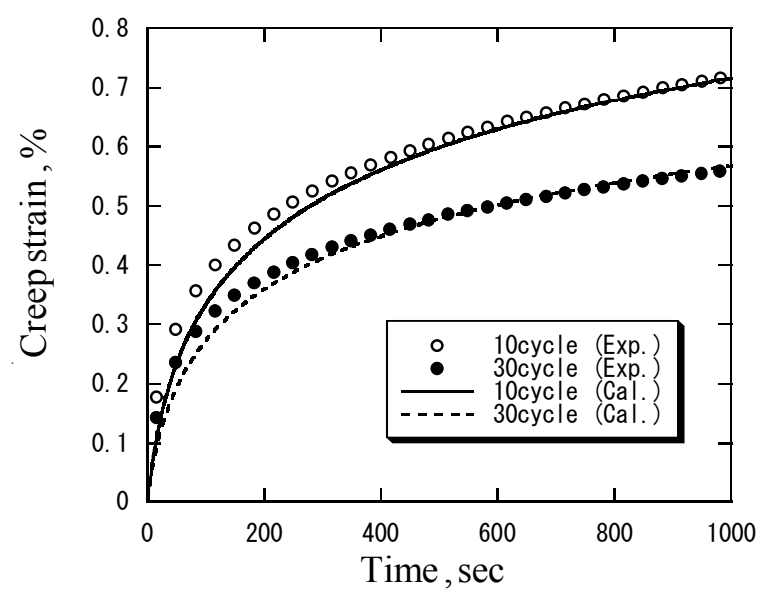

Fig.4 Subsequent creep curves during 1000second after cyclic preloading

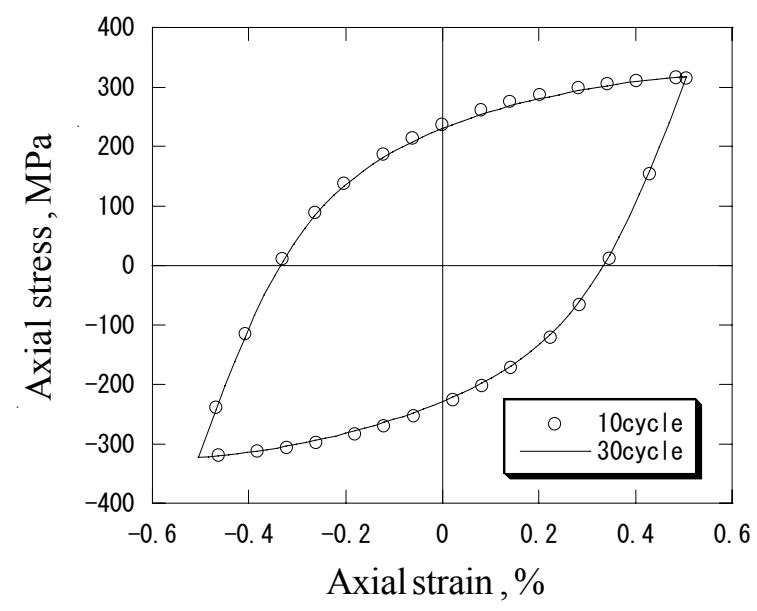

Fig.3 Stress-strain curves of 10th and 30th cycle of tension-compression cyclic loading

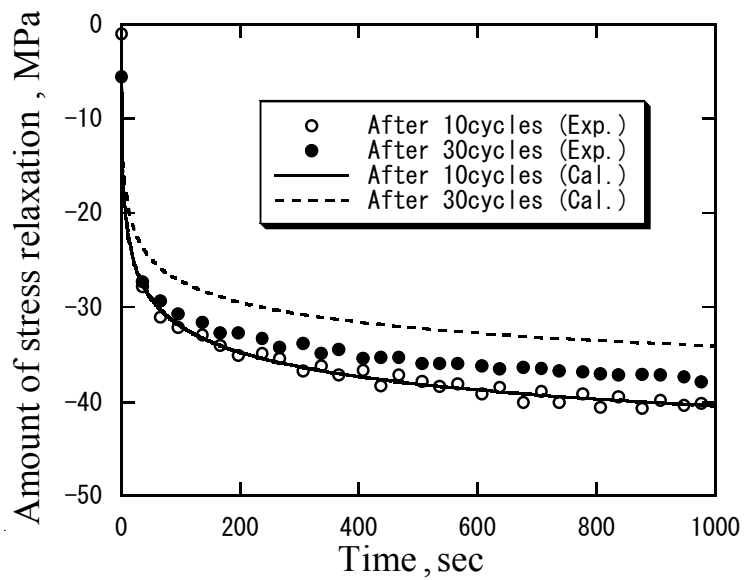

Fig.5 The relations between the amount of stress relaxation after cyclic preloading and time

\section{Experimental Results}

Tension Compression Cyclic Loading Fig. 2 shows the relation between the tensile peak stress and number of cycle during tension-compression cyclic loading. The cyclic loading was conducted under the strain rate of $0.01 \% / \mathrm{sec}$ with the strain amplitude of $0.5 \%$. It can be seen that initially the cyclic hardening occurs until $20^{\text {th }}$ cycle and after that, the cyclic softening is observed. Figure 2 also shows that the peak stresses of $10^{\text {th }}$ and $30^{\text {th }}$ cycle are almost same. In Fig. 3 the symbol $(\circ)$ and solid line show the stress-strain curves of $10^{\text {th }}$ and $30^{\text {th }}$ cycles of the cyclic loading. It can be seen that the stress-strain curves of them are also almost same.

Subsequent Creep Tests In Fig.4 the symbols $(\circ)$ and $(\bullet)$ show the subsequent creep curves during 1000 seconds at the stress levels of $315 \mathrm{MPa}$. The creep tests were conducted after the 10 and 30 cycles of the tension-compression cyclic preloading under the strain rates of $0.01 \% / \mathrm{sec}$ with the strain amplitude of $0.5 \%$. It can be seen that the subsequent creep strain after 30 cycle of the cyclic loading is clearly smaller than that after 10 cycles although these stress-strain curves of the cyclic preloading are almost same as shown in Fig.3. 

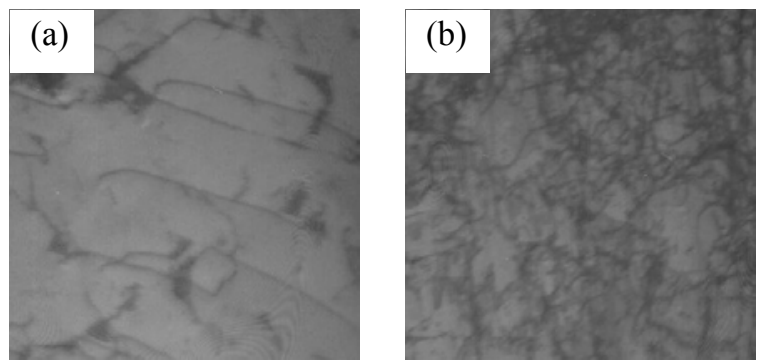

Fig.6 Dislocation structures after (a) 10 and (b) 30 cycles of tension-compression cyclic loading

\begin{tabular}{c|c|c|c|c|c|c|c|c}
\hline $\mathrm{K}[\mathrm{MPa}]$ & $\mathrm{a}_{\mathrm{h}}$ & $\mathrm{a}_{\mathrm{s}}$ & $\alpha_{\mathrm{h}}$ & $\alpha_{\mathrm{s}}$ & $\mathrm{b}$ & $\mathrm{n}$ & $\mathrm{R}_{\text {sat }}[\mathrm{MPa}]$ & $\eta$ \\
\hline 0.05 & 0.15 & 0.35 & 0.5 & 0.41 & 0.03 & 10 & 80 & 0.6 \\
\hline $\mathrm{D}_{\text {sat }}[\mathrm{MPa}]$ & $\beta$ & $\mathrm{m}_{0}$ & $\mathrm{~m}_{1}$ & $\mathrm{~m}_{2}$ & $\mathrm{c}$ & $\lambda$ & $\mathrm{H}_{\text {sat }}[\mathrm{MPa}]$ & $\mathrm{h}$ \\
\hline 204 & 0.1 & 8 & 5 & 6.2 & 0.08 & 0.26 & 130 & 0.25 \\
\hline
\end{tabular}

Table1 Material constants for Type 304 stainless steel at room temperature

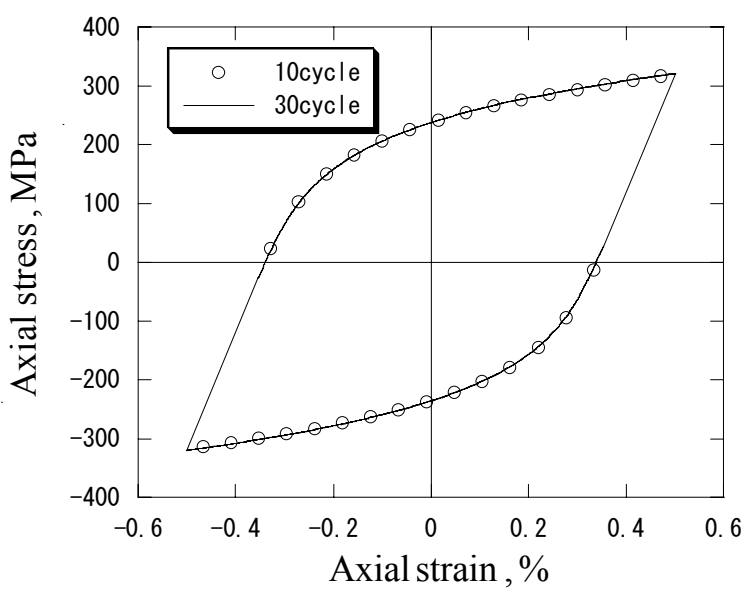

Fig.7 Simulated stress-strain relations of 10th and 30th cycle of cyclic loading

Subsequent Stress Relaxation Tests In Fig.5 the symbols ( $($ ) and $(\bullet)$ show the relations between the relaxed stress and time during 1000 seconds. These stress relaxation tests were conducted at tensile strain $0.5 \%$ after 10 and 30 cycles of tension-compression cyclic loading under the strain rates of $0.01 \% / \mathrm{sec}$ with the strain amplitude of $0.5 \%$. It can be seen that the amount of the stress relaxation after 30 cycles is smaller that after 10 cycles although the stress-strain curves of them were almost same. Namely, Fig.4 and Fig.5 show that time-dependent deformation decreases with the increase in the number of cycle of the cyclic preloading.

\section{Discussions}

TEM Observation In Fig.6 (a) and (b) show the dislocation structures of the specimens after 10 and 30 cycles of the cyclic loading respectively. It can be seen that the dislocation structures after 10 and 30 cycles of the cyclic loading are clearly different although the stress-strain curves are almost same as shown in Fig.3. Therefore, this observation suggest that the change of the dislocation structures lead to the different the subsequent creep and the subsequent stress relaxation as shown in Fig.4 and Fig.5.

Numerical Simulations The dislocation density increase with the number of cycle of cyclic preloading. And the dislocation density affects on the subsequent time dependent deformations as shown above. As shown in Eq.(10), the material constant $\mathrm{H}$ is multiplier of viscoplastic strain rate. And the amount of time-dependent deformation is changed due to $\mathrm{H}$. Therefore, assuming that the dislocation density increase with the accumulated viscoplastic strain, the material constant $\mathrm{H}$ should be a function of the accumulated viscoplastic strain as

$$
\mathrm{H}=\mathrm{H}_{\text {sat }}\left\{1+\eta \exp \left(-\int\left|\dot{\bar{\varepsilon}}^{v}\right| d t / h_{s}\right)\right\} .
$$

where $\mathrm{H}_{\text {sat }}, \eta$, and $h_{s}$ are the material parameters. To represent the both of the cyclic hardening and the cyclic softening in Fig.2 the Eq.(14) is also rewritten by

$$
\mathrm{D}=\mathrm{D}_{\text {sat }}\left\{1-\alpha_{h} \exp \left(-\int\left|\dot{\bar{\varepsilon}}^{v}\right| d t / a_{h}\right)+\alpha_{s} \exp \left(-\int\left|\dot{\bar{\varepsilon}}^{v}\right| d t / a_{s}\right)\right\} .
$$


In Eq.(17), $\mathrm{D}_{\text {sat }}, \alpha_{h}, a_{\mathrm{h}}, \alpha_{s}$ and $a_{\mathrm{s}}$ are the material parameters. Using these equations and the best fit material constants as shown in Table1 the numerical simulations were conducted.

In Fig.7 the symbol (O) and the solid line show the simulated stress-strain curves of 10th and 30th cycle of the tension-compression cyclic loading corresponding to Fig.3. The simulated stress-strain relations of $10^{\text {th }}$ and $30^{\text {th }}$ cycle of the cyclic preloading are well agree with each other as same as the experimental result shown in Fig.3.

The solid line and the broken line in Fig.4 show the simulated subsequent creep curves. The simulated creep curves are different due to the number of cycle of the cyclic preloading. It can be seen that calculations have good agreements with experimental results.

The solid line and the broken line in Fig.5 show the simulated subsequent stress relaxation. The simulated stress relaxations are different due to the number of cycle of the cyclic preloading. And the amount of the stress relaxations is also well simulated.

\section{Conclusions}

In this paper, the subsequent time dependent deformations after cyclic loading were discussed. To simulate the subsequent time-dependent deformation a constitutive model was proposed. As the results, the following conclusions were obtained:

(1) The subsequent creep tests after 10 and 30 cycles of tension-compression cyclic loading showed that the creep strain decrease due to the increase of cyclic preloading although the stress-strain curves of $10^{\text {th }}$ and $30^{\text {th }}$ cycle of cyclic preloading were almost same.

(2) The amount of stress relaxation after 30 cycles is smaller than that after 10 cycles although the stress-strain curves of $10^{\text {th }}$ and $30^{\text {th }}$ cycle of cyclic preloading were almost same.

(3) From the microscopic observations by using TEM, the dislocation structures after 10 and 30 cyclic preloading were clearly different although the stress-strain curves of $10^{\text {th }}$ and $30^{\text {th }}$ cycle of cyclic loading were almost same. These results suggest that the change of microstructures effects on the subsequent time-dependent deformations.

(4) The proposed constitutive model successfully simulated both the tension-compression cyclic preloading and the subsequent time dependent deformations.

\section{Acknowledgment}

The authors appreciate the financial support of Hattori Houkoukai (Japan). TEM observation was conducted at Center for Advanced Research of Energy Technology, Hokkaido University. The supports are gratefully acknowledged.

\section{References}

[1] Ohno, N.: J. Appl. Mech. Vol.49 (1982), pp.721

[2] Krempl, E.: Acta Mech. Vol.69 (1987), pp.25

[3] McDowell, D. L.: J. Appl. Mech. Vol.54 (1987), pp.323

[4] Freed, A. D. and Walker, K. P.: Int. J. Plast. Vol.9 (1993), pp.213

[5] Teodosiu, C. and Zaiqian, H.: Proc. NUMIFORM ‘95 (1995), pp.173

[6] Estrin, Y., Braasch, H., and Brechet, Y.: J. Eng. Mater. Technol. Vol.118 (1996), pp.441

[7] Kaneko, K. and Oyamada, T.: Int. J. Plast. Vol.16 (2000), pp.337

[8] Bari, S. and Hassan, T.: Int. J. Plast. Vol.18 (2002), pp.873

[9] Yaguchi, M., Yamamoto, M., and Ogata, T.: Int. J. Plast. Vol.18 (2002), pp.1083

[10] Yoshida, F. and Uemori, T.: Int. J. Plast. Vol.18 (2002), pp.661

[11] Mayama, T., Sasaki, K., and Ishikawa, H.: Key Eng. Mat. Vol.233-236 (2003), pp.83 
[12] Chaboche, J.L.: Int. J. Plast. Vol.5 (1989), pp.247 